\title{
Pricing the Limits to Growth from Minerals Depletion
}

\section{Citation}

Weitzman, Martin L. 1999. Pricing the limits to growth from minerals depletion. Quarterly Journal of Economics 114(2): 691-706.

\section{Published Version}

http://dx.doi.org/10.1162/003355399556025

\section{Permanent link}

http://nrs.harvard.edu/urn-3:HUL.InstRepos:3708467

\section{Terms of Use}

This article was downloaded from Harvard University's DASH repository, and is made available under the terms and conditions applicable to Other Posted Material, as set forth at http:// nrs.harvard.edu/urn-3:HUL.InstRepos:dash.current.terms-of-use\#LAA

\section{Share Your Story}

The Harvard community has made this article openly available.

Please share how this access benefits you. Submit a story.

\section{Accessibility}




\title{
PRICING THE LIMITS TO GROWTH \\ FROM MINERALS DEPLETION
}

\author{
MARTIN L. WEITZMAN
}

\begin{abstract}
This paper evaluates the loss of global welfare from exhaustion of nonrenewable resources, such as oil. The underlying methodology represents an empirical application of some recent developments in the theory of green accounting and sustainability. The paper estimates that the world loses the equivalent of about 1 percent of final consumption per year from finiteness of the earth's resources, compared with a counterfactual trajectory where global extraction of minerals is allowed to remain forever constant at today's flow rates and extraction costs.
\end{abstract}

\section{INTRODUCTION}

Spurred by the "energy crisis," a severe loss of confidence erupted on the world scene of the 1970s concerning the planet's ability to cope with exhaustion of nonrenewable resources such as oil. The ensuing debate about "limits to growth" was hardly the first expression of such concerns. Nor is it likely to be the last, as this general theme seems to repeat itself periodically throughout history. ${ }^{1}$

Why doesn't this issue ever get resolved? To be more specific here, take the example of petroleum. Why can't economics come up with a credible estimate of what "running out of oil" will cost the world in terms of the implied limits to growth of future consumption?

To ask this question is al most to answer it. I magine what kind of a modeling effort would be required to give a full evaluation. It would presumably involve solving a computable general equilibrium model having dynamic specifications of oil demand and supply response functions, a sophisticated treatment of expectations, knowledge of world oil reserves and exploration costs, estimates of elasticities of substitution between oil and all other relevant factors of production, sectoral projections of technological progress, learning curves, macroeconomic growth forecasts, and so forth, and so on. Furthermore, at the end of the day, any answers would only be as believable as the estimates, projections, and assumptions behind the model.

Yet, there is another possible approach here-from the dual

1. As just one famous example, Stanley J evons was worried about coal exhaustion in 1865.

(1) 1999 by the President and Fellows of Harvard College and the Massachusetts Institute of Technology.

TheQuarterlyJ ournal of E conomics, May 1999 
side. Rather than trying to get at the problem frontally by direct specification, suppose that we took more of an indirect approach by looking at the relevant prices. After all, we know in a general way that a lot of information is compressed into a price. To take an extreme example here, we have always sensed intuitively that if the world is going to exhaust its oil reserves within a few generations, and if, additionally, there were to be disastrous consequences for living standards of the people alive at that time, then it should show up now in a relatively "high" price of today's oil. Conversely, if today's price of oil is comparatively "low," it must mean that the limits to growth from running out of oil are not so constraining-in some sense.

The question then becomes can we turn this kind of a qualitative heuristic story into a more exact quantitative method for "pricing out" the limits to growth from minerals depletion. The answer is yes, under certain circumstances, and it involves an application of the modern theory of comprehensive or "green" national income accounting.

This paper has two aims. The primary aim is to provide an empirical assessment of the limits to growth from minerals exhaustion by appropriately "pricing out" depletion. A secondary aim is to introduce - by using an actual specific example-a way of reasoning, class of models, and set of issues that characterize the contemporary economic theory of "green accounting" and "sustainability."

We start with the simplest possible formulation that captures the essence of the problem. Later we discuss where and how this simple model generalizes.

\section{THE MOdel}

Suppose that a stylized aggregated economy consists of three basic types of goods. Consumption $\mathrm{C}$ and net investment I are interchangeably manufactured, whilethe natural resource $E$ is an intermediate good extracted from an exhaustible stock. Throughout the paper consumption will serve as the numeraire. Let investment also be valued at a price of one, while the comparable net price (price minus marginal extraction cost) of a unit of the exhaustible resource is $P$.

A naive measure of net produced income might be $C+I$. However, this measure disregards resource depletion. Suppose that we conceptualize income more broadly as representing the 
largest permanently maintainable level of consumption. ${ }^{2}$ Suppose further that we think of PE as being a form of temporary income that happens to come out of a finite stockpile under the ground, but is otherwise perfectly substitutable with $\mathrm{C}$ or I. Then, converting both manufactured investment and extracted income linearly into "as-if consumption," the expression,

$$
C+I-P E \text {, }
$$

might be seen as representing the largest permanently maintainable level of consumption, with the temporary income term

$$
\text { PE }
$$

being a "welfare cost" of resource exhaustability, because it represents the nonpermanent part of naively measured present income $\mathrm{C}+\mathrm{I}$ that cannot be counted upon for the future.

The main problem with the above argument is the assumption of perfect substitutability between $\mathrm{C}, \mathrm{I}$, and $\mathrm{E}$. While it might be all right to regard manufactured consumption and manufactured investment as trading off against each other linearly (indeed, interchangeability of $\mathrm{C}$ and $\mathrm{I}$ is the standard assumption in almost all aggregative growth models), it is quite another matter to pretend that $\mathrm{E}$ is also linearly substitutable with $\mathrm{C}$ or I over a nonmarginal range.

Actually, the complicated nonlinear way in which the exhaustible resource interacts with capital when it enters the production process will largely determine economic performance over time. A lot will hinge on the degree of substitutability between $\mathrm{K}$ and $\mathrm{E}$. Therefore, this aspect of the problem must be expressed quite generally in a paper dedicated to analyzing the limits to growth from declining $\mathrm{E}$. Nevertheless, the paper shows that as long as $C$ and I areinterchangeably produced (as in the traditional formulation), the above simple story identifying PE as the welfare cost of depletion is essentially correct. Perhaps surprisingly, a standard linear trade-off between $C$ and I is sufficient to drive the powerful result that what looks like a marginal valuation of $E$, which by rights should hold only locally, in actuality possesses the strong global interpretation of the simplestory.

We begin with the most basic plausible model for analyzing the limits to growth.

Let $K(t)$ be the aggregate stock of capital at time $t$, with

2. See, e.g., Hicks [1946], Chapter 14. 
corresponding net investment flow I (t). Let $\mathrm{S}(\mathrm{t})$ be the aggregate stock of nonrenewable resources (hereinafter oil, for short) at time $t$, whose corresponding extraction flow rate is denoted $E(t)$. Let $\mathrm{X}(\mathrm{t})$ represent manufacturing capacity at timet.

We treat here a technology of the form,

$$
X(t)=F(K(t), E(t)),
$$

where $F(K, E)$ is the aggregate net production function, while $X$ represents productive capacity.

In the spirit of the abstraction underlying traditional macroeconomic aggregation, which treats manufactured consumption and manufactured investment as if they are essentially differently packaged products of the same production capacity, we assume here thelinear trade-off,

$$
\mathrm{C}(\mathrm{t})+\mathrm{I}(\mathrm{t})=\mathrm{X}(\mathrm{t}) \text {. }
$$

The corresponding accumulation equations are

$$
\dot{K}(\mathrm{t})=\mathrm{I}(\mathrm{t}),
$$

and

$$
\dot{S}(\mathrm{t})=-\mathrm{E}(\mathrm{t})
$$

The production system (3)-(6) represents about the simplest meaningful way to combine the Ramsey and Hotelling models. Note two basic underlying assumptions. The exhaustible resource E enters only through the aggregate production function, while C and I are perfect substitutes. These two assumptions strike meas entirely reasonable at the level of abstraction appropriate to this aggregate model, but they will end up driving the strong results that follow.

$\mathrm{N}$ ote that no assumptions are being made about how $\mathrm{K}$ and $\mathrm{E}$ interact, so that in principle the aggregate net production function (3) could take virtually any form. The central question at this level of aggregation is the extent to which reproducible capital $\mathrm{K}$ can be used to offset the limits to growth posed by running out of the exhaustible resource $\mathrm{E}$. The model does not prejudge this issue, but rather allows us to infer an answer empirically, which is the main point of the paper.

The model is closed here by supposing a dynamic competitive equilibrium with real rate of return $r$. This means a trajectory $\left\{\mathrm{C} *(\mathrm{t}), \mathrm{K} *(\mathrm{t}), \mathrm{S}^{*}(\mathrm{t}), \mathrm{P} *(\mathrm{t})\right\}$ along which is simultaneously satisfied 
the conditions,

$$
\begin{gathered}
\left.\frac{\partial \mathrm{F}}{\partial \mathrm{K}}\right|^{*}=\mathrm{r}, \\
\left.\frac{\partial \mathrm{F}}{\partial \mathrm{E}}\right|^{*}=\mathrm{P} *(\mathrm{t}), \\
\frac{\dot{\mathrm{P}} *(\mathrm{t})}{\mathrm{P} *(\mathrm{t})}=\mathrm{r} .
\end{gathered}
$$

In defense of equation (7), I think it fair to state as a stylized fact that the own rate of return on consumption has been essentially trendless over time. ${ }^{3}$ One could argue that the measurable entity corresponding most closely to this concept is the annual after-tax real return on capital (because it approximately defines the relevant intertemporal consumption trade-off faced by the average citizen in deciding how much to save). As a very rough approximation, a trendless round figure of 5 percent might be used for this interest rate in the postwar period. ${ }^{4}$

The dual variable $\mathrm{P} *(\mathrm{t})$ represents the price minus marginal extraction cost of a barrel of oil in the ground at timet, sometimes called the "net price" or "Hotelling rent." Equation (8) specifies that in competitive equilibrium the Hotel ling rent or net price of a barrel of oil in the ground just equals its above-ground net valuein production. Formula (9) is the famous Hotelling rule, which indicates the asset pricing path that must be followed by an exhaustible resource in competitive equilibrium.

How might we describe development of the model economy (3)-(9)? Over time, oil is running out. Behind the scenes, an attempt is being made to substitute the services of capital for the services of oil. The outcome depends on many things-including how large are ultimate oil reserves, how severe is the effect of diminishing returns to capital, and, most especially, the degree to which accumulated capital can replace oil. With a low elasticity of substitution, there may be severe limits to growth. (In the most

3. This is one of Kaldor's famous "stylized facts" about the growth of advanced industrial economies. (F or a discussion see Sol ow [1970], p. 3.) N ordhaus [1994], in his section titled "Empirical Evidence on the Return on Capital" on p. 125, summarizes a number of studies that are consistent with a trendless interpretation.

4. Nordhaus [1995], J orgenson [1994], or Feldstein [1997] could each be cited to justify this very rough conclusion about lack of persistent trend fluctuating around 5 percent per year. 
extreme case, where $\mathrm{E}$ is an essential input, $\mathrm{C} *(\mathrm{t})$ must tend to zero over time, so that life as we know it would eventually cease.) Conversely, a sufficiently high elasticity of substitution presents much less of a threat to eventual well-being.

The whole point of the paper is that we would like to have some empirical sense, using current readily available indicators, about which ones among the above possible features actually characterize our world, and therefore what sort of growth scenario awaits us in the future.

As we have noted, a number of considerations determine the actual welfare losses associated with finiteness of oil stocksincluding the ultimate size of these stocks, the eventual degree of diminishing returns to capital, and the limiting elasticity of substitution between capital and oil-none of which are readily observable now. Thus, in undertaking the numerical exercise of this paper, we are essentially being challenged to predict at the present time what will happen in the future.

We wish to pose rigorously the following question. "What is the welfare loss from running out of oil?" In answering this question, we must, in effect, project not only what future history will be, but also the counterfactual thought experiment of what future history would be if we never ran out of oil. To begin with, then, we need a base-case measure of welfare, against which we can calibrate the outcome of the counterfactual thought experiment we need to perform.

As a first step on this path, let us agreeto measure wel farefor the base case of the actual world we happen to live in (where stocks of oil are finite) by the simple linear indicator:

$$
W^{*}=\int_{0}^{\infty} C^{*}(\mathrm{t}) \mathrm{e}^{-r t} \mathrm{dt}
$$

In words, our measure of welfare here is the present discounted value of consumption, where the discount rate is the competitive-equilibrium own rate of return on consumption generated by the economy itself. There are several possible ways of defending the above form as a welfare indicator. First of all, (10) is intuitively appealing, being just a weighted sum of consumption where the weights are, naturally, based on "the" interest rate. At perhaps a somewhat deeper level, we are assuming that the economy here is acting as if it is implicitly maximizing an objective function of the form (10), so why not use this same linear form explicitly to approximate the changes in welfare associated 
with the counterfactual thought experiment we are about to perform? ${ }^{5}$

The guiding spirit of this paper is not fancy. We are not expecting anything more than a rough estimate. All we are looking for is some handle on an important problem where none currently exists. We are using a very simple model. Here we will be satisfied just to have some sense of the average difference in consumption between our own world, where we will someday run out of oil, and a hypothetical world where we never run out of oil. For these purposes (10) is a more than adequate indicator.

Now we come to a serious modeling issue. We want to answer the foll lowing question. "What is the welfare loss from running out of oil?" But then, in effect, we must specify what it means for future history to unfold in a world just like our own, except that "oil never runs out."

In our actual world, present consumption of oil is $E *(0)$, and it must (eventually) decline over time because oil stocks are limited. Now suppose that this were not so. Suppose that we interpret "never running out" of oil to mean that we have been given a miraculous gift of many spigots distributed throughout the world, which deliver a total flow of $\mathrm{E}^{*}(0)$ barrels of oil per year every year, forever, at this year's real extraction costs. In other words, suppose that, instead of being nonrenewable, oil was a renewable resource. The counterfactual historical thought experiment being proposed here is to imagine what would happen to consumption if everything else were the same in the world economy except that, instead of being constrained by the finite world stock of oil S(0), we were instead constrained by this year's flow of oil $E^{*}(0)$, so that oil will never become any scarcer than it is now. ${ }^{6}$ What, we want to know, would then happen to consumption?

Let $\left\{\mathrm{C}^{* *}(\mathrm{t}), \mathrm{K} * *(\mathrm{t})\right\}$ be a solution of the following hypothetical optimal growth problem:

maximize

$$
\int_{0}^{\infty} C(t) e^{-r t} d t
$$

5. Along with a transversality condition (unstated here), equations (7)-(9) represent the necessary duality conditions for the optimal control problem of maximizing an objective function of the form (10) subject to (3)-(6) with $S(t) \geq 0$, $\mathrm{K}(\mathrm{t}) \geq 0$. For more on this duality interpretation see Weitzman [1976]. I mplicitly, equations (7)-(9) are describing an interior solution.

6. An alternative approach would assume that the real price of oil remains forever constant at today's level, while the economy is rebated the amount it spends on oil as a lump sum transfer. This approach gives the same answer, but it is slightly more difficult to analyze. 
subject to

$$
\mathrm{C}(\mathrm{t})+\mathrm{I}(\mathrm{t})=\mathrm{F}\left(\mathrm{K}(\mathrm{t}), \mathrm{E}^{*}(0)\right),
$$

and

$$
\dot{\mathrm{K}}(\mathrm{t})=\mathrm{I}(\mathrm{t}),
$$

and starting from the aggregate capital stock being today's actual value $\mathrm{K}(0)$.

Then define

$$
\mathrm{W}^{* *} \equiv \int_{0}^{\infty} \mathrm{C} * *(\mathrm{t}) \mathrm{e}^{-\mathrm{rt}} \mathrm{dt}
$$

and

$$
\frac{\Delta \mathrm{W}}{\mathrm{W}} \equiv \frac{\mathrm{W}^{* *}-\mathrm{W}^{*}}{\mathrm{~W}^{* *}} .
$$

In the paper, $\Delta \mathrm{W} / \mathrm{W}$, defined above, is taken to be an appropriate measure of the world's "welfare loss from running out of oil." This expression might be described fairly as representing the average percentage difference in consumption between the two scenarios.

\section{The Main Result}

It might be feared that it is difficult or impossible to actually determine $\Delta \mathrm{W} / \mathrm{W}$ because a lot of information seems to be required. Actually, the needed information is reduced here to a simple form requiring only knowledge of current indicators. The following proposition represents the main theoretical result.

Proposition. For the model of this paper,

$$
\frac{\Delta W}{W}=\frac{P^{*}(0) \cdot E^{*}(0)}{C *(0)+I^{*}(0)} .
$$

Proof of the Proposition. We are, in effect, comparing the solutions of two optimal growth problems here. The first problem $(*)$, which maximizes (10) subject to (3)-(6), is interpreted here as if being a description of the actual history of the economy. The second optimal growth problem $(* *)$ maximizes the same objective function (11), but under the alternative counterfactual constraints (12) and (13). 
We then wish to compare $\mathrm{W}^{*}=\int \mathrm{C} *(\mathrm{t}) \mathrm{e}^{-\mathrm{rt}} \mathrm{dt}$ with $\mathrm{W}^{* *}=$ $\int C^{* *}(\mathrm{t}) \mathrm{e}^{-\mathrm{rt}} \mathrm{dt}$. To help us with this task, we can invoke here a fundamental valuation result, which states that, for a timeindependent economy in dynamic competitive equilibrium, current inclusive NDP is the annuity equivalent of future consumption. ${ }^{7}$

Applying this result in turn to economies $(*)$ and $(* *)$, we can then write

$$
C^{*}(0)+I^{*}(0)-P^{*}(0) \cdot E^{*}(0)=r W^{*}
$$

and

$$
C^{* *}(0)+I^{* *}(0)=r W * * .
$$

From the structure of the two optimal growth problems, it must hold that

$$
\mathrm{C}^{*}(0)+\mathrm{I} *(0)=\mathrm{F}\left(\mathrm{K}(0), \mathrm{E}^{*}(0)\right)
$$

and

$$
\mathrm{C}^{* *}(0)+\mathrm{I} * *(0)=\mathrm{F}(\mathrm{K}(0), \mathrm{E} *(0)) .
$$
(16).

Plugging (17)-(20) into (15), we then have the desired result

The proposition has the following interpretation. In this simple economy what would be measured by a national income statistician as "conventional NDP" is

$$
\mathrm{NDP}_{\text {conventional }}=\mathrm{C} *(0)+\mathrm{I} *(0) \text {. }
$$

Expression (21) is clearly a misleading indicator of the power to produce-and hence to consume-over time, because it fails to account properly for the role that depletable oil plays in propping up current production at artificially high levels. Intuitively, future production possibilities would seem to be more completely captured by the "green NDP" expression:

$$
\mathrm{NDP}_{\text {gren }}=\mathrm{C}^{*}(0)+\mathrm{I} *(0)-\mathrm{P} *(0) \cdot \mathrm{E}^{*}(0) \text {. }
$$

The simple-minded heuristic answer to the question, "What is the average loss from running out of oil," is the difference between $\mathrm{NDP}_{\text {conventional }}$ and NDP green:

$$
\Delta \mathrm{W}=\mathrm{P} *(0) \cdot \mathrm{E}^{*}(0) .
$$

7. This is a translation of the basic message in Weitzman [1976]. Note that everything is intended to be evaluated at the constant rate of interest. 
The theorem can then be interpreted to say that, in this economy, the above simple-minded heuristic answer is exactly the correct response to a rigorously posed version of the (counterfactual) question that is being asked. The result is somewhat striking because a marginal valuation is being used, in this particular instance, to evaluate a discrete change.

Beforeapplying this result empirically, we should understand better how far the theorem can be stretched to include more realistic situations. Toward this end, we now sketch what would be the appropriate extension of the basic idea to cover (1) multiple capital goods, (2) multiple exhaustible minerals, (3) a more general net production function where extraction costs of minerals may increase as remaining stocks decline, (4) technological progress, and (5) some other issues.

Turning to the first task, consider a multisector generalization of the one-sector Ramsey technology, where the production possibilities frontier is now an n-dimensional hyperplane rather than a two-dimensional straight line trade-off between consumption and investment. A little reflection reveals that the critical assumption in the proof of the main theorem is thelinearity of the surface describing current production possibilities between the single consumption good and the $n-1$ investment goods, not its dimensionality. As long as the curvature of the current production possibilities frontier is relatively small (over the range of changes induced in current consumption-investment patterns by the counterfactual thought experiment of never running out of oil), the proof goes through.

A straight-line transformation between $\mathrm{C}$ and $\mathrm{I}$ is the standard unchallenged assumption in aggregative growth theorybecause it greatly simplifies the analysis and we cannot tell a convincing story why the price of I should change systematically relative to the price of $C$. I think the same logic holds here. We have little notion of how running out of exhaustible forms of energy will affect the relative price of capital and might as well adopt the standard assumption here.

The model has thus far treated just one exhaustible resource. But there is no difficulty making an extension to cover the general situation of $\mathrm{m}$ different nonrenewable minerals. In this case $\mathbf{E}$ is interpreted as a vector of $m$ resource extraction flows, while $\mathbf{P}$ stands for the corresponding m-vector of net resource prices.

N ote the extreme generality of the above interpretation of $\mathbf{K}$ and $\mathbf{E}$ as multidimensional input vectors, in the sense that the 
aggregate production function $X=F(K, E)$ is permitted to take virtually any form. Furthermore, there is no problem in allowing net production to vary with the stocks of remaining minerals, so that $X=F(\mathbf{K}, \mathbf{E}, \mathbf{S})$, which is a way of modeling dependence of extraction costs on remaining stocks. In this case the simple Hotelling rule is modified into a more complicated generalization, but all of the conclusions of the model remain.

As for technological progress, when there is a residual shift-factor present, then the production system is no longer time-independent. I n this case, the fundamental valuation result (17) is replaced by the more inclusive expression,

$$
\mathrm{rW}^{*}=\mathrm{C}^{*}(0)+\mathrm{I}^{*}(0)-\mathrm{P} *(0) \cdot \mathrm{E}^{*}(0)+\mathrm{T}^{*}(0),
$$

where $\mathrm{T}^{*}(0)$ is a residual term that captures the power of time-dependent atmospheric shift factors like technological progress, which are not accounted for, to increase annuityequival ent consumption by expanding the production possibilities frontier over time. ${ }^{8}$ Assuming that technological progress increases production possibilities in both worlds by the same "atmospherically neutral" shift, then

$$
\mathrm{rW}^{* *}=\mathrm{C}^{* *}(0)+\mathrm{I} * *(0)+\mathrm{T}^{*}(0),
$$

and

$$
\frac{\Delta W}{W}=\frac{P^{*}(0) \cdot E^{*}(0)}{C^{*}(0)+I^{*}(0)+T^{*}(0)} .
$$

The above specification of technological progress amounts to postulating here a base case where the present discounted value of residual shift factors is the same in both worlds. As with the relative price of capital, we have littlenotion of how running out of exhaustible forms of energy will affect the overall pace of technological progress, compared with the alternative scenario, and some kind of neutrality assumption seems like a reasonable place to begin the analysis.

Turning, finally, to some remaining issues, there are many other features of the model that might legitimately be criticized. For example, there is no treatment of uncertainty; there is no deep reason to believe that the own rate of return to consumption should be constant or that private and public rates should

8. For a more detailed explanation, with some calculations, see Nordhaus [1995], Weitzman [1997], or Weitzman and Löfgren [1997]. 
coincide; thereis no good justification for projecting past growth of the technological progress residual into the future; the perfectly competitive rational-expectations perfect-foresight story behind the formation of Hotelling prices warrants much more scrutiny; the effects of environmental externalities, like various forms of pollution or congestion, are ignored by implicitly being held constant in the background; the level of aggregation is so extreme that every sector of every country in the world is being lumped together as if having the same technology; and so forth, and so on. To these, and yet other, criticisms, I can merely plead that this model is intended only to deliver up a few rough theoretical insights and to allow some crude empirical calculations to be made about an important set of questions that had previously gone largely unanswered. I think of this model primarily as representing a kind of "base-case-neutral" specification for analyzing the overall effect of running out of minerals-in the loose sense that it seems difficult to argue there exists herea systematic bias pointing in one direction or the other.

The upshot of this brief discussion, I hope, is that the (modified) theorem essentially holds as a reasonable base case even for somewhat more complicated and realistic scenariosprovided that the model is appropriately understood as an approximation.

We turn now to the empirical part of the paper.

\section{How Much Do We Lose from RunNing out of Minerals?}

Having posed rigorously the question "What is the loss of global welfare caused by exhaustion of mineral resources?" and having answered it theoretically in a simple model, we now turn to the primary task of the paper, which is to estimate it empirically.

We start this numerical exercise by closely following the format of the main result.

World GDP in 1994 is estimated by the World Bank to be $\$ 25.223$ trillion. ${ }^{9}$ To convert into (conventionally measured) World NDP, we use here the corresponding U. S. ratio for 1994, which is $N P_{\text {conventional }} / G D P \sim .88 .{ }^{10}$ With this same imputed ratio for capital depreciation, our estimate for conventionally measured world NDP in 1994 is $\$ 22.2$ trillion.

9. World Bank [1996], p. 211.

10. USGNP (1994) = 6932; USCNNP (1994) = 6113 (in billion dollars). Source: U. S. Commerce Department [1996], Table 1.9 on page D-4. 
TABLE I

WORLD RENTS, 1994

Source: Modified World Bank Estimates

\begin{tabular}{|c|c|c|c|c|c|c|}
\hline Commodity & Units & $\begin{array}{l}\text { Price } \\
(\$)\end{array}$ & $\begin{array}{l}\text { Unit } \\
\text { cost } \\
(\$)\end{array}$ & $\begin{array}{l}\text { Marginal } \\
\text { cost }(\$)\end{array}$ & $\begin{array}{l}\text { Quantity } \\
\text { (thousands) }\end{array}$ & $\begin{array}{l}\text { Hotelling } \\
\text { rents } \\
\text { (million \$) }\end{array}$ \\
\hline $\begin{array}{l}\text { Crude oil } \\
\text { Natural }\end{array}$ & metric tons & 113 & 40.4 & 56.6 & $3,012,984$ & 169,932 \\
\hline gas & T-joules & 2,133 & 684.5 & 958.3 & 95,925 & 112,683 \\
\hline $\begin{array}{l}\text { Hard coal } \\
\text { Brown coal }\end{array}$ & metrictons & 40 & 29.6 & 32.6 & $3,967,054$ & 29,356 \\
\hline (lignite) & metrictons & 11 & 8.5 & 9.4 & $1,119,937$ & 1,792 \\
\hline Bauxite & metrictons & 33.8 & 13.2 & 14.5 & 132,315 & 2,554 \\
\hline Copper & metrictons & 2,330 & 1259.3 & $1,385.2$ & 9,539 & 9,012 \\
\hline Iron ore & metric tons & 40 & 21.7 & 23.9 & 604,679 & 9,735 \\
\hline Lead & metrictons & 679 & 598.3 & 658.1 & 2,718 & 57 \\
\hline Nickel & metrictons & 6,278 & 4763.5 & $5,239.9$ & 783 & 813 \\
\hline Phosphate & metric tons & 38 & 28.8 & 31.7 & 136,482 & 860 \\
\hline Tin & metrictons & 5,428 & 3826.4 & $4,209.0$ & 166 & 202 \\
\hline Zinc & metrictons & 1,033 & 813.1 & 894.4 & 6,964 & 965 \\
\hline Gold & kilograms & 12,346 & 9838.8 & $10,822.7$ & 1,741 & 2,651 \\
\hline Silver & metric tons & 169,872 & 117966.8 & $129,763.5$ & 10 & 411 \\
\hline Total & & & & & & 341,023 \\
\hline
\end{tabular}

In Table I are presented estimates of world Hotelling rents in 1994 for the fourteen most significant exhaustible minerals. Underlying data are from the 1997 World Bank study, Expanding the Measure of Wealth. ${ }^{11}$ All in all, the price and quantity data seem fairly reliable, with the weakest link here being the imputed world shadow price for restricted-trading minerals like natural gas and lignite. ${ }^{12}$ One can have qualms about assuming the current price of oil or some other minerals to be an unbiased estimate of the true shadow price, but there would have to be a sizable discrepancy to influence the final results of this paper. The unit cost data are a measure of average cost of production, including depreciation of fixed assets and return on capital. ${ }^{13}$ They apparently were collected from a wide variety of sources of

11. I am indebted to Kirk Hamilton for making available to methe underlying estimates of prices, quantities, and unit costs for each of the fourteen mineral classes, but he should not be blamed for the way I have used them in this paper.

12. These are estimated by an f.o.b. export price index. See World Bank [1997], p. 17.

13. See World Bank [1997], pp. 8 and 17. 
varying quality, but, overall, they seem sufficiently accurate for the purposes of this paper.

I estimate marginal cost to be about 40 percent higher than unit (average) cost for crude oil and natural gas, while being about 10 percent higher for all remaining minerals in Table I. Such estimates are loosely consistent with what other studies find. ${ }^{14}$ While my guesstimates here are very rough indeed, little of substance is hanging on exact values, which in any case are impossible to pin down exactly.

Hotelling rents are then estimated as "price minus marginal cost" times "quantity."

The ratio of world Hotelling rents to conventionally measured NDP in 1994 is then

$$
\left(\mathrm{P} *(0) \cdot \mathrm{E}^{*}(0)\right) /(\mathrm{C} *(0)+\mathrm{I} *(0))=.34 / 22.2 \sim 1.5 \% .
$$

Turning to technological progress, it has been estimated, ${ }^{15}$ for the period from about 1950 to the present, that, as a very rough empirical approximation,

$$
(\mathrm{T} *(0)) /(\mathrm{C} *(0)+\mathrm{I} *(0)) \sim 40 \% .
$$

If the "Solow residual" of nonimputed atmospheric change continues to grow at about its postwar rate, so that (28) can be extrapolated into a projection, then (26) yields

$$
\frac{\Delta \mathrm{W}}{\mathrm{W}} \sim 1.1 \%
$$

It should be emphasized that alternative methods of estimation, or different data, are unlikely to change the "big picture" that emerges from this numerical exercise. In particular, it is difficult for me to think how $\Delta W M$ could reasonably be made much larger than an upper bound of, say, about 2 percent.

\section{ConCluding Discussion}

Using the methodology of this paper, I estimate that the fact that we happen to live in a world where all fourteen minerals listed in Table I are exhaustible, rather than being renewable, [1987].

14. See, e.g., Pindyck [1978], Mueller [1985], Stollery [1983], and Pindyck

15. See the very rough estimates in Weitzman [1997] and Weitzman and Löfgren [1997], based on two different methodologies. 
causes us overall to lose the equivalent of about 1 percent of average consumption each year.

How should we think about the outcome of this numerical exercise? Does 1 percent of world consumption per year represent a large or a small loss of welfare?

In absolute terms, 1 percent of world consumption represents an enormous amount of goods and services, being equivalent today to about 250 billion current dollars per year. Such an amount exceeds the GDP of over 95 percent of the countries now occupying seats in the U. N. General Assembly. If the world economy grows at 2 percent per annum, the capitalized value of forgone consumption at a 5 percent interest rate comes to over eight trillion present dollars, which represents a truly staggering welfareloss!

In relative terms, however, such numbers are not nearly big enough to justify viewing finiteness of world mineral reserves as posing a serious limit to future growth of the world economy. I think the relevant insight here is that the welfare correction to NDP for nonattributed technol ogical change, although admittedly but an extremely rough estimate, is maybe 40 times larger than the required adjustment for depletion of exhaustible resources. In some sense it might be said figuratively that, other things being equal, policy concerns about running out of oil should carry only about one-fortieth the weight of policy concerns about the effectiveness of $R \& D$.

Of course, any conclusion is only as good as the assumptions of the underlying model. As our workhorse model we have chosen here the simplest imaginable hybrid of the standard Ramsey and Hotelling formulations, with a touch of the Solow residual thrown in. Then we rely heavily on market prices being decent indicators of true scarcity values. And this is just the beginning of a long list of built-in assumptions. It is quite legitimate to criticize many of these assumptions. And, of course, different implications will follow from different assumptions. Even so, I think the following conclusion is fair.

In its amazingly compressed reduced form, the information contained in the prices of minerals can be loosely translated as if "the market" is rendering its best judgment of the overall welfare loss from running out of minerals. This is a judgment rendered not by a computer-driven forecasting model, but by millions of actual buyers and sellers staking their own private fortunes on the outcome. With this loose interpretation, it seems as if "the market 
believes" that there are sufficient possibilities for substitution and innovation that the ultimate exhaustion of nonrenewable re sources represents about a 1 percent diminution of our overall consumption.

So long as human ingenuity is capable of such examples as fiber optics, we will possibly never need all of the copper reserves that theoretically exist. I think the spirit of the model is trying to say to us that it sees a world which looks like this example. There may well be serious limits to growth. But they are probably for reasons other than exhaustion of standard mineral resources that pass through the marketplace.

HARVARD UNIVERSITY

\section{References}

Feldstein, Martin, "The Costs and Benefits of Going from Low Inflation to Price Stability," Chapter 3 in C. D. Romer and D. H. Romer, eds., Reducing I nflation: M otivation and Strategy (Chicago, I L: University of Chicago Press, 1997).

Hicks, J ohn R., Value and Capital, second edition (Oxford, UK: Oxford University Press, 1946).

J orgenson, Dale W., "Investment and Economic Growth," The Simon Kuznets Lectures, Yale University, November 11-13, 1994

Manthy, Robert S., Natural Resource Commodities-A Century of Statistics (Baltimore, MD: J ohns Hopkins U niversity Press, 1978).

Mueller, Michael J., "Scarcity and Ricardian Rents for Crude Oil," Economic Inquiry, XXIII (1985), 703-724.

Nordhaus, W. D., Managing the Global Commons (Cambridge, MA: The MIT Press, 1994).

, "How Should We Measure Sustainable I ncome?" mimeo, October 1995.

Pindyck, Robert S., "Gains to Producers from the Cartelization of Exhaustible Resources," Review of E conomics and Statistics, LX (1978), 238-251. "On Monopoly Power in Extractive Resource Markets," L ournal of Environmental Economics and Management, XIV (1987), 128-142.

Solow, Robert M., Growth Theory (Oxford, U K: Oxford U niversity Press, 1970).

Stollery, Kenneth R., "Mineral Depletion with Cost as the Extraction Limit: A Model Applied to the Behavior of Prices in the Nickel Industry," L ournal of Environmental Economics and Management, X (1983), 151-165.

U. S. Commerce Department, Survey of Current Business, LXXVI (12), (December 1996).

Weitzman, Martin L., "On the Welfare Significance of National Product in a Dynamic E conomy," Quarterly l ournal of Economics, XC (1976), 156-162. "Sustainability and Technical Progress," Scandinavian ] ournal of E conomics, XCIX (1997), 1-13.

Weitzman, M. L., and K.-G. Löfgren, "On the Welfare Significance of Green Accounting as Taught by Parable," ournal of Environmental E conomics and Management, XXXII (1997), 139-153.

WorldBank, World Development Report (Oxford, UK: Oxford University Press, 1996).

, Expanding the Measure of Wealth: Indicators of Environmentally Sustainable Devel opment (Washington, DC: The World Bank, 1997). 
This article has been cited by:

1. Volker H. Hoffmann, Timo Busch. 2008. Corporate Carbon Performance Indicators. Journal of Industrial Ecology 12:4, 505-520. [CrossRef]

2. Yasuhisa HAYASHIYAMA, Shin-ichi MUTO, Tetsuji SATO. 2005. OPTIMAL ECONOMIC GROWTH THEORY IN THE ENVIRONMENTAL AND RESOURCE ECONOMICS: ECONOMICS FOR SUSTAINABLE DEVELOPMENT. Doboku Gakkai Ronbunshu :779, 25-44. [CrossRef] 